\title{
Study on Biofouling and photo catalytic activity on Titanium tube well condensers
}

\author{
A. Jayachitra ${ }^{1}$, A.Rajalakshmi ${ }^{1}$ N.Krithiga ${ }^{1}$, R.Indhu ${ }^{2}$ \\ ${ }^{I}$ Department of Plant Bio-technology, School of Biotechnology, Madurai Kamaraj University, Madurai- \\ 6250021, India \\ ${ }^{2}$ Department of Biotechnology, Bharathidasan University, Tiruchi, India.
}

\begin{abstract}
Biofouling in titanium tube-well condensers can cause a serious problem in heat exchange process and its products. Photo catalytic activity a chemical treatment enhancing the anatase thin films characterization which is present on the surface of the titanium material in degrading the efficacy of the microbial populations like Pseudomonas, Klebsiella, Bacillus, Acinetobacter which stick on the tube-well condensers. The titanium material exposed to $30 \mathrm{~V}$ of current for an timing of about 48 hours showed to be possessing high efficiency in maintenance of the material. The colony counts and Biochemical characterization proved that treatment process in Titanium metal exposed to fresh water system facilitates in Biofouling cleaning methodology. This study was confirmed by a mechanical process, a sponge ball cleaning shows that there is a considerable weight loss in biofouled condenser tubes, rather increasing the adherence efficacy of the organism than the inhibition. Thus, the problems related to Titanium biofouling and its effect on the products can be rectified.
\end{abstract}

Key words: Biofouling, biofilm, corrosion, photo catalytic activity, sponge ball cleaning

\section{Introduction}

Titanium and its alloys have extensively used in widespread applications including aerospace engines and airframes, military hardware, cryogenic equipment, geothermal plants, metal extraction equipment, nuclear waste storage facilities, springs, ultracentrifuges, vehicle armour etc., Titanium possesses outstanding resistance to corrosion in a wide range of aggressive to corrosion. It is essential immune to pitting and crevice corrosion. It can resist erosion in clean waters at velocities up to $9 \mathrm{~m} / \mathrm{s}$ ad is totally resistant to attack by Hydrogen Sulfide, Nitrites and Ammonia and Ferrous ion compounds. The reason for the remarkable corrosion resistance exhibited by this material relies on the presence of the inert, strongly adherent surface oxide film, which forms almost instantly on exposure to moisture, air and many sources of oxygen. This oxide film is self-healing and exceptionally stable over a range of $\mathrm{pH}$ and potentials in conditions ranging from highly oxidizing to mildly reducing (Schutz, 1991). Titanium is an extremely reactive metal and spontaneously forms an oxide layer on contact with air or traces of moistre. Three polymorphs of titanium dioxide occur in nature rutile, anatase and brookite. Of these, anatase form of $\mathrm{TiO}_{2}$ exhibits photo catalytic activity under near-UV light illumination. Numerous studies have been focused on the unique performance of $\mathrm{TiO}_{2}$-in photo catalytic degradation of toxic compounds, such as DDT, dichloronitroenzene, trichloroethane, $\mathrm{H}_{2} \mathrm{~S}, \mathrm{NO}$ and $\mathrm{Cr}$ (VI), etc (Noguchi et al., 2004).

Biofouling is the term used to describe the undesired development of microbial layers on surfaces. Such microbial layers are termed biofilms. The term has been adapted from heat exchanger technology where fouling is generally defined as the undesired deposition of biological material on heat transfer surface (Epstein, 1981).A biofilm is an assemblage of surface-associated microbial cells(organic and inorganic, living and dead material) that is enclosed in an extra cellular polymeric substance matrix. The components of biofilms constitute bacteria, diatoms and bacterial exopolymer. Werner Borchard et al., in 1998 described that biofilm play one in the water technology technically and economically meaning role, both in desired form and biofilm reactors as also unwanted with Biofouling and biocorrosion. Flemming et al., (2004) described that it is reasonable to assess the possibilities of fouling situation to keep biofilm development under control.

\section{Sample collection}

\section{Methods}

The sample was collected from freshwater a source was from an open reservoir located near Chennai Petro Chemicals Limited, Chennai. Here three different of sample were analyzed in this fresh water those involving in biofouling on titanium material collected from cooling towers. This reservoir is used as an intermediate storage facility for ground water collected from nearby river basin.

Titanium material (Grade 2) 
Study on Biofouling and photo catalytic activity on Titanium tube well condensers Composition of Commercial Purity (CP) Titaium (Grade 2)

\begin{tabular}{|c|c|c|c|c|c|c|}
\hline Elemen & $\mathrm{C}$ & $\mathrm{Fe}$ & $\mathrm{N}_{2}$ & $\mathrm{O}$ & $\mathrm{H}_{2}$ & $\mathrm{Ti}$ \\
\hline$\overline{\mathrm{Wt}} \%$ & $<0.1$ & $\begin{array}{c}<0.3 \\
\end{array}$ & $<0.3$ & 0.25 & 0.12 & $\mathrm{Bal}$ \\
\hline
\end{tabular}

\section{Specimen preparation}

Ti6A14V titanium alloy samples were in the form of discs $30 \mathrm{~mm}$ diameter. The commercial purity titanium (Grade 2) specimens used in the laboratory studies were obtained by cutting titanium sheets into small coupons of sizes $30 \mathrm{~mm}$ X $20 \mathrm{~mm}$ X $1 \mathrm{~mm}$.

\section{Acid pickling}

Prior to subjecting the titanium surface to any further surface modification the as received samples were pickled in an acid bath for 10 minutes with agitation to remove the naturally formed oxide layer and also to rid the surface of surface stains. The composition of the acid bath is as follows: Nitric acid: $400 \mathrm{~g} / \mathrm{L}$, Hydrofluoric acid: $40.0 \mathrm{~g} / \mathrm{L}$

After 10 minutes the coupons were picked up and ultrasonicately cleaned (5mins) using soap solution in an ultrasonicator. The coup coupons were then rinsed using distilled water and then wiped dry using tissue paper.

\section{Surface modification by anodization}

Anodization was carried out at $25^{\circ} \mathrm{C}$ in a beaker containing orthophosphoric acid (30g/L) as the electrolyte and stainless steel as the cathode. The sample required to be anodized was suspended in the center of the cathode fully immersed in the electrolyte using a $2 \mathrm{~mm}$ diameter titanium rod. The titanium coupons are provided with $2 \mathrm{~mm}$ diameter holes through which the titanium rod passes for providing electrical contact.

Anodization was carried out at three different voltages for four different holding times. Samples were anodized for $10 \mathrm{~min}, 1 \mathrm{~h}, 24 \mathrm{~h}$ and $48 \mathrm{~h}$ at $30 \mathrm{~V}, 50$ and $100 \mathrm{~V}$. Anodized surfaces displayed a range of beautiful colors blue, Yellow and pink at $30 \mathrm{~V}, 50 \mathrm{~V}$ and $100 \mathrm{~V}$ respectively. The change in color with holding time is as indicated. The acid pickled coupons were used as control surfaces in these studies.

\section{Evaluating the Photo catalytic Activity}

The photo catalytic activity of the anodized titanium surfaces was evaluated by methylene blue (MB) degradation method using acid pickles coupons as control surfaces. Anodized titanium coupons as well as acid pickled control coupons, six coupons of the respective experimental condition were immersed I separate petridishes containing $25 \mathrm{ml}$ methylene blue $(2 \mathrm{mg} / \mathrm{L})$ solution and it was irradiated by BLB lamps. A UV-Vis spectrophotometer was used to estimate the concentration of the unreacted MB by measuring the attenuation at its absorption maximum of $660 \mathrm{~nm}$ at $2 \mathrm{~h}$ intervals up to $10 \mathrm{~h}$ and the final measurement was taken at $24 \mathrm{~h}$ and $48 \mathrm{~h}$.

\section{Laboratory set up for exposing test surfaces to microbial cultures}

Exposure studies were conducted in a cylindrical glass vessel containing the exposure medium. A glass rod positioned centrally in the glass vessel supported the glass pegs, which bore the coupons. The specimens were illuminated by six numbers of black light blue (BLB) fluorescent lamps (4W, Philips) arranged in a hexagonal configuration surrounding the test vessel. The light produced by BLB lamps has wavelengths range of 350-380nm and hence is referred to as near-UV light to distinguish it from the UV light used normally for disinfection. The near-UV light used in the study is not having any bactericidal property and it is transmitted through ordinary glass. Therefore, no quartz vessel was used for the study.

\section{Exposure studies conducted using freshwater}

In order to study the effectiveness of the test surfaces in controlling microbial fouling, the test surfaces were exposed to microbial flora and fauna present in freshwater under laboratory conditions. The source of freshwater was from an open reservoir located near Chennai Petro Chemicals Limited. This reservoir is used as an intermediate storage facility for ground water collected from Palar river bed. The reservoir, which has a storage area of 1.7 hectares and a depth of $2.28 \mathrm{~m}$ at overflow level, has a storage capacity of $28,400 \mathrm{~m}^{3}$. The industrial uses of this water are as feed water to the cooling condensers of CPCL.

The seawater used in the laboratory studies was obtained from the treated cooling water from the CPCL (having about 0.1 to $0.3 \mathrm{ppm}$ residual chlorine). The source of seawater for the cooling water system was the coastal waters of Ennore. 


\section{Exposure studies}

The freshwater exposure studies were conducted by filter in $2 \mathrm{~L}$ of reservoir water using 0.45 micron Millipore filter paper and concentrating the biofilm forming components in the water and adding residue in the filter paper to $500 \mathrm{~mL}$ of reservoir water.

\section{Post Exposure Analysis}

Total viable counts (TVC)

Three coupons of each experimental condition (triplicate experiments) were used for total viable count estimation. The coupons $(30 \mathrm{~mm} \times 20 \mathrm{~mm} \times 1 \mathrm{~mm})$ were removed from the medium and gently washed to remove loosely adhering cells and the bacterial cells on the coupons were dispersed into $15 \mathrm{ml}$ sterile phosphate buffer $\left(0.0425 \mathrm{~g} \mathrm{KH}_{2} \mathrm{PO}_{4}, 0.19 \mathrm{~g} \mathrm{MgCl}_{2}\right.$ per liter) by ultrasonication for $10 \mathrm{~min}$. The length of sonication for optimum recovery of cells was found to be $10 \mathrm{~min}$. The ultrasonically cleaned surfaces were stained and observed to ensure complete recovery of cells. In case of freshwater exposure studies, TVC were taken by plating in nutrient agar. The number of colony forming unite per $\mathrm{cm}^{2}$ of the coupon was calculated as follows;

C.F.U $/ \mathrm{cm}^{2}$ of coupon =

Where, Volume of suspension

Volume plated

Area of coupon (Titanium grade 2 )

Colonies counted x Dilution x Volume of suspension

\section{Direct Acridine Orange Count (DAOC):}

Two coupons of each experimental condition exposed in the nutrient culture were used for direct microscopic observation. The coupons were gently washed with sterile water and air-dried in a sterile chamber and the coupon surface was flooded using Acridine orange drained off and the coupons were washed in sterile water, dried and observed./ Acridine orange, a fluorescent dye, differentially stains single intercalated with the former and green while complexing with the latter when observed under a Nikon Eclipse E600 epifluorescence microscope (excitation filter BP 490:barrier filter O 515). Thus, the number of orange fluorescing cells depicts the actively metalizing cells on the anodized and acid pickle titanium surfaces and the green fluorescing cell fluorescing cells in ten randomly chosen fields were counted and cells per $\mathrm{cm}^{2}$ was calculate using the following formula,

Number of cells $/ \mathrm{cm}^{2} \quad=\quad \frac{\text { Average number of cells per field }}{\text { Where, Field area }=0.0078 \mathrm{~cm}^{2}}$

\section{Isolation of Microorganisms from Biofilm}

Serial dilutions of the bacterial cell suspension were prepared add $0.1 \mathrm{ml}$ of each dilution was plated onto nutrient agar. The plates were incubated for $24-48 \mathrm{hrs}$ at $37^{\circ} \mathrm{C}$ and the number of colonies counted. Mean TVC values were calculated for each coupon and the results are expressed as colony forming units (cfu) per $\mathrm{cm}^{2}$, colony forming units per $\mathrm{cm}^{2}$ was calculated using the formula,

C.F.U/cm ${ }^{2}$ of coupon $=$ Colonies counted X Dilution X Volume of suspension

Where, Volume of suspension Volume plated X Area of coupon in $\mathrm{cm}^{2}$

Volume plated

Area of Titanium grade 2 sheets

$$
\begin{aligned}
& =50 \mathrm{~mL} \\
& =0.1 \mathrm{~mL} \\
& =220 \mathrm{~cm}^{2}
\end{aligned}
$$

General Count (bacterial count) biofilm dispersed in $50 \mathrm{~mL}$ sterile buffer was serial diluted to $10^{3}$ dilutions and $0.1 \mathrm{ml}$ each dilution was plated in nutrient agar by pour plate method. The medium was autoclaved at $121^{\circ} \mathrm{C}(15 \mathrm{psi})$ for 15 minutes. The plates were incubated for $3-4$ days at $37^{\circ} \mathrm{C}$ before the colonies were counted.

\section{Molecular characterization}

\section{Colony morphology:}

The colonies formed on the agar plates were observed and the cultural characteristics of the colonies, including shape, size, texture, elevation, growth, density, margins, and appearance

Simple staining

Bacterial smear was prepared and heat fixed prior to staining. Then the smear was flooded with crystal violet staining solution, dried and examined under microscope. 


\section{Gram staining}

Bacterial smear was prepared by heat fixation. Then the slide was flooded with crystal violet staining reagent for 1 minute then added gram's iodine mordant for 1 minute washed with water for 2 seconds. Then smear was immersed in $95 \%$ ethanol for 30 seconds and immersed in counter stain for 2 min, finally the smear was examined under the microscope.

\section{Biochemical characterization}

The following biochemical tests were performed with the isolates to characterize

\section{Motility determination- hanging drop experiment}

A cover slip and a cavity slide were cleaned add a loop full of log phase culture was placed in the center of cover glass was inverted down carefully to make the drop hanging cavity and was observed in high power oil immersion microscope.

\section{Triple sugar ion test}

A loopful of culture was streaked in triplet sugar ion agar slants was kept for incubation for $37^{\circ} \mathrm{C}$.

\section{Test for citrate utilization}

The culture has been inoculated in a tube containing Simmons Citrate agar. It was incubated at $37^{\circ} \mathrm{C}$ for 1 day. In Simmons Citrate agar containing bromothymol blue as indicator which changes from green to blue (Prussian blue color).

\section{Oxidase test}

Young colonies were picked up from the agar plate using a sterile toothpick. Then the cells were smeared on what man 1 filter paper impregnated with 2-3 drops of $1 \% \mathrm{~N}-\mathrm{N}$ ' tetra methyl p-phenylene diamine $\mathrm{HCl}$ reduced with sodium thionate or reduced $0.2 \%$ dichlorophenol indophenols) (DCPIP) solution prepared in $0.1 \%$ ascorbic acid. Color change was observed.

Nitrate reduction test

The ability of the isolates to reduce nitrate to nitrite, ammonia and nitrogen was assessed. Potassium nitrate broth was prepared and sterilized. The tubes were inoculated with the test culture and incubated at $37^{\circ} \mathrm{C}$ for $3-5$ days.

\section{Citrate utilization test}

Simmons citrate agar was prepared and it was sterilized at $121^{\circ} \mathrm{C}$ for 15 mins and the medium was allowed to solidify in the slanting position, the culture was inoculated and incubated for $18-24 \mathrm{hrs}$ the color change from blue to green indicates positive.

\section{Starch hydrolyzing test}

In the starch agar medium, the activity of amylase can be determined where the test organism was inoculated on the starch agar medium and incubated for overnight at $37^{\circ} \mathrm{C}$ the plate was floated with iodine , decanted and observed for the zone of clearances around the colonies.

\section{Lipid hydrolyzing test}

Tributyrin agar was used to demonstrate the hydrolytic activities of the exoenzyme lipase were the positive result was seen by formation of opaqueness of the medium.

\section{Catalase test}

A loopful of culture grown on nutrient agar plate for 24-48 hrs was taken. Then the loop was placed in $1 \% \mathrm{H}_{2} \mathrm{O}_{2}$ on a glass slide. Then the slide was observed for the production of air bubble with effervescence.

\section{Isolation of genomic DNA}

The following steps were involved in the genomic DNA isolation. Take1.5 ml of culture was taken in a micro centrifuge tube and pelleted out (centrifuged at $10,000 \mathrm{rpm}$ for 5 minutes). The pellet was resuspended in 500 microlitre of TE buffer. $300 \mu \mathrm{l}$ of lysozyme was added and was incubated at $37^{\circ} \mathrm{C}$ for 30 minutes. $60 \mu \mathrm{l}$ of SDS and $3 \mu \mathrm{l}$ of Proteinase $\mathrm{K}$ was added and mixed and incubated at $55^{\circ} \mathrm{C}$ for 2 hours. After incubation, equal volume of Tris saturated phenol $(900 \mu \mathrm{l})$ was added. The mixture was centrifuged at 10,000 rpm for 10 minutes. The supernatant was transferred to a fresh tube and equal volume of PCI (Phenol: Chloroform: Isoamyl alcohol) was added. The extraction was repeated until no protein precipitate was obtained at interface. The aqueous phase was transferred to a fresh tube and added 0.1 volumes of 3M Sodium Acetate ( $\mathrm{pH} 5.5$ ). Mixed gently and added 2.5 volume of the ice cold Ethanol. Mixed by inverting the tubes. Incubated the mixture at $-80^{\circ} \mathrm{C}$ for 30 
minutes. It was centrifuged at 10,000 rpm for 10 minutes and then discarded the supernatant. To pelleted DNA, equal volume of $70 \%$ ethanol was added and centrifuged at 10,000 rpm for 10 minutes. The supernatant was discarded. The pellet was dried and dissolved in $100 \mu \mathrm{l}$ of TE buffer. $20 \mu \mathrm{l}$ of DNA was loaded in $1 \%$ Agarose gel.

PCR amplification of 16S rRNA gene

TEST:

Total volume 50 $\mu \mathrm{l}$

Genomic DNA $=3 \mu 1$

8F Primer $\quad=2.5 \mu 1$

1490R Primer $\quad=2.5 \mu \mathrm{l}$

Bioron master mix $\quad=20 \mu 1$

Deionized water $\quad=22 \mu 1$

Control:

Total volume 50 $\mu \mathrm{l}$

Genomic DNA $=3 \mu 1$

Forward Primer $=2.5 \mu \mathrm{l}$

Reverse Primer $=2.5 \mu \mathrm{l}$

Deionized water $=42 \mu \mathrm{l}$

Amplification cycle for 16S rRNA gene

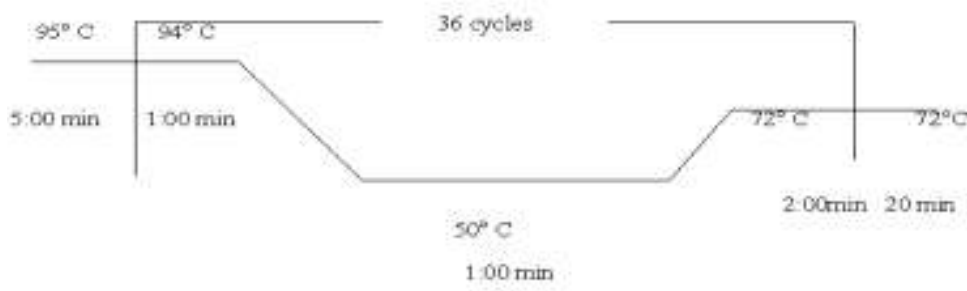

Separation of amplified PCR products

$12 \mu \mathrm{l}$ of amplified PCR product was loaded in the 1\%Agarose gel electrophoresis.

\section{Results}

The oxide surface film of the titanium surface material showed an maximum enhanced photo catalytic activity at an voltage of $30 \mathrm{~V}$ exposed for 48 hours resembling an blue colouration, in addition to their increased thickness as shown in figure 1. Sponge ball cleaning in titanium tube condensers was studied that through they makes an considerable weight loss of biofouled layers but it enhances the adherence of biofilms to it. Total viable count assay confirms that less number of cells was found to be present in the photo catalytic activity (30V for 48 hours) induced surface layers. The results were tabulated in table 1. Epifluorescence studies viewed on through direct Acridine orange count (DAOC) depicted only very few metabolically active cells in the photocatalysed Titanium films. They were visualized as shown in the Figure 2 and 3 . The results were tabulated in Table 1. Biochemical and molecular characterization of the isolates strictly adhered to Titanium material were analyzed and the results were tabulated as in Table 2. The isolated DNA were subjected to amplification process and they were confirmed by the analyses with Agarose Gel Electrophoresis technique. The bands obtained for isolated and amplified DNA samples were showed in Figure 4 and 5. The amplified DNA of the isolates was observed.

\section{Discussion}

The photo catalytic inhibition of microbial attachment was also found to be dependent on the cell wall characteristics of the organisms (Judy et al., 2003).The gram negative Pseudomonas species with a lipoproteinaceous outer membrane was the most susceptible to the photo catalytic effect, while the Gram positive Bacillus species with peptide glycan cell wall showed moderate susceptible and the algae with siliceous cell was showed no susceptible at all. Thus the total viable cell count of microorganisms in biofilms seems to be less and an anodized of $30 \mathrm{~V}$ for 48 hours, where maximum inhibition of photo catalytic activity reveals. Other than sponge cotton balls, abrasive sponge ball, carborundum sponge balls and nylon brush were used in a ratio of 1 ball per two days for cleaning biofouled surfaces (Nosetani et al., 1981). Biochemical characterization and microbial identification of the isolates were found. Extracellular polymeric substances play an significant role in biofilm formation by trapping the nutrients, immobilizing them available for bacteria in the biofilm (Sutherland, 1984).In Gram negative bacteria quorum sensing signals, structural proteins and some genes 
Study on Biofouling and photo catalytic activity on Titanium tube well condensers

involves in the increased expression of biofilm iniation responding to adhesion and auto aggregation. One extracytoplasmic protein $(\mathrm{ClpP})$ plays a role in interactions with an abiotic surface; the osmolarity of the medium also affects the ability of the cell to form biofilms. In these organisms Severn adjacent genes involves, named pel genes forming pellicle at the air-liquid interface are responsible for the production of a glucose-rich matrix material required for the formation of biofilms. In Gram positive bacteria motility and chemo taxis seems to be associated with the initial steps of biofilm formation. Critically, the eps operon, which is believed to be responsible for the biosynthesis of an exopolysaccharide that binds chains of cells together in bundles.

\section{Reference}

[1] Epstein, N. (1981) Fouling: technical aspects. In: Somerscales EFC, Knudsen, J.G., (eds). Fouling of heat transfer equipment. Hemisphere, Washington. 31: 110-119.

[2] Flemming, H.C., Schaule. G. and Ridgway. H.F. (2004) Living with biofilms-elements of an integrated anti-fouling strategy. Institute of Interface Biotechnology, University of Duisburg-Essen, Geibelstr. 41: 47-69.

[3] Judy, G., George, R.P., Muraleedharan, P., and Khatak, H.S. (2004) Photo catalytic inhibition of Microbial Adhesion by Anodized Titanium. Corrosion science. 20: 167-175.

[4] Noguchi, D., Kawamata, Y and Nagatomo, T. (2004) Titanium Dioxide in photo catalytic degradation of Toxic Compounds. Journal of the electrochemical society. 151 (7): 61-65.

[5] Nosetani, T., Sato, S., Onda, K., Kashiwada, J., and Kawaguchi, K. (1981) Effect of Marine Biofouling on the Heat Transfer Performance of Titanium Condenser Tubes. Sumitomo Light Met. Tech. Rep. 22(2):30-41.

[6] Schutz, R.W., (1991) A Case for Titanium's Resistance to Microbially Influenced Resistance. Materials Performance 30:58-67.

[7] Sutherland, I.W., (1984) Microbial exopolysaccharides-their role in microbial adhesion in aqueous systems. CRC Crit Rev. Microbiol. 10: 173-187.

Table 1. Enumeration of Bacterial biofilms on Modified Titanium Surfaces

\begin{tabular}{|l|l|l|}
\hline Observation methods & $\begin{array}{l}\text { Photo catalytic Activity } \\
\text { Colony Forming Units }\end{array}$ & $\begin{array}{l}\text { Sponge Ball cleaning } \\
\text { Colony Forming Units }\end{array}$ \\
\hline Total Viable count & $31 \times 10^{2}$ cells & $113 \times 10^{2}$ cells \\
\hline Direct Acridine Orange Count & $13 \times 10^{2}$ cells & $12 \times 10^{2}$ cells \\
\hline
\end{tabular}

Table-2 Biochemical Characterization of Bacterial Isolates.

\begin{tabular}{|c|c|c|c|c|c|c|c|c|c|c|}
\hline 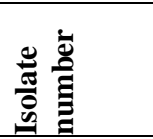 & 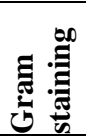 & 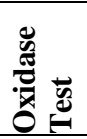 & 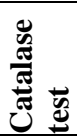 & 莺 & $\stackrel{\frac{0}{\theta}}{\underline{\Xi}}$ & 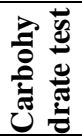 & 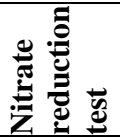 & 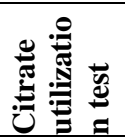 & 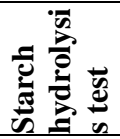 & 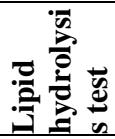 \\
\hline Isolate 1 & + & - & + & + & - & + & + & - & + & - \\
\hline Isolate 2 & + & - & + & - & - & + & + & + & + & - \\
\hline Isolate 3 & - & - & + & - & - & + & + & + & + & - \\
\hline Isolate 4 & - & + & + & + & - & + & + & + & + & - \\
\hline Isolate 5 & + & - & + & - & - & + & + & + & + & - \\
\hline Isolate 6 & + & - & + & - & - & + & + & + & + & - \\
\hline Isolate 7 & + & - & + & - & - & + & + & + & + & - \\
\hline Isolate 8 & + & - & + & - & - & + & + & + & + & - \\
\hline Isolate 9 & - & - & + & - & - & + & + & + & + & - \\
\hline Isolate 10 & - & + & + & + & - & + & + & + & + & - \\
\hline Isolate 11 & - & + & + & + & - & + & + & + & + & - \\
\hline Isolate 12 & - & + & + & + & - & + & + & + & + & - \\
\hline Isolate 13 & - & + & + & + & - & + & + & + & + & - \\
\hline Isolate 14 & - & + & + & + & - & + & + & + & + & - \\
\hline
\end{tabular}

Figure-1 Titanium Anodized for 48 hours

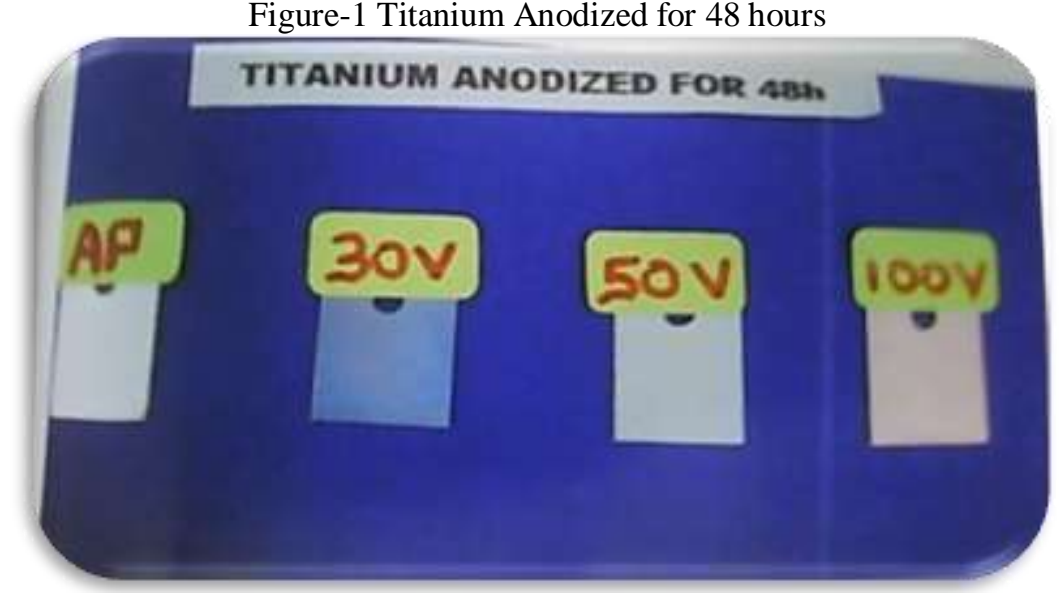

www.iosrjournals.org 
Figure-2 Direct Acridine Orange Count (DAOC)

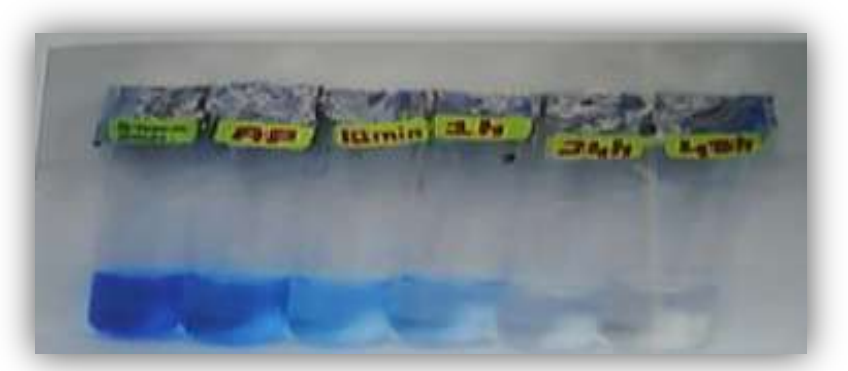

Figure-3 Direct Acridine Orange Count (DAOC) epifluorescent staining

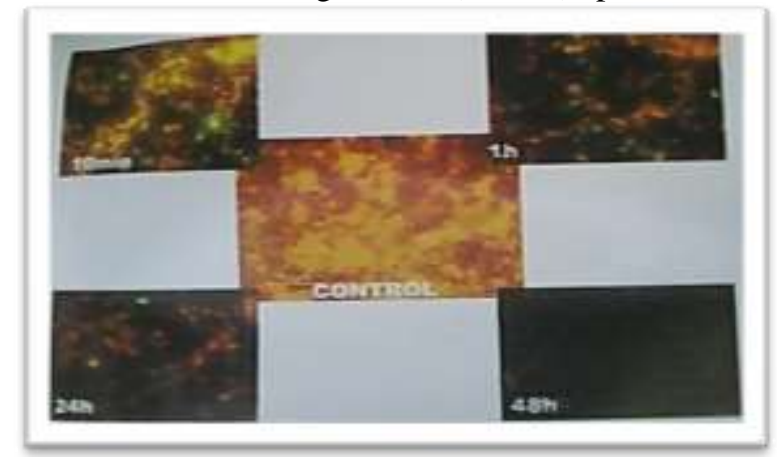

Figure-4 Isolated Genomic DNA

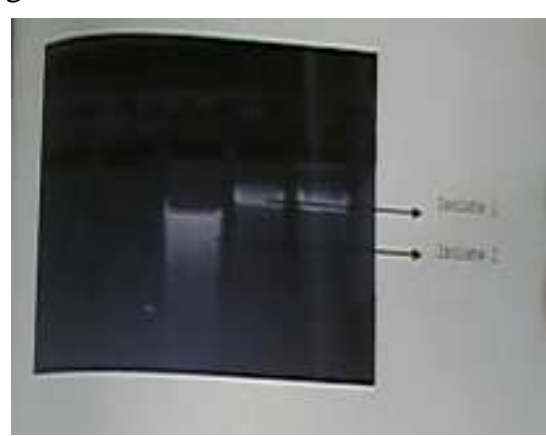

Figure 5Amplified PCR Products

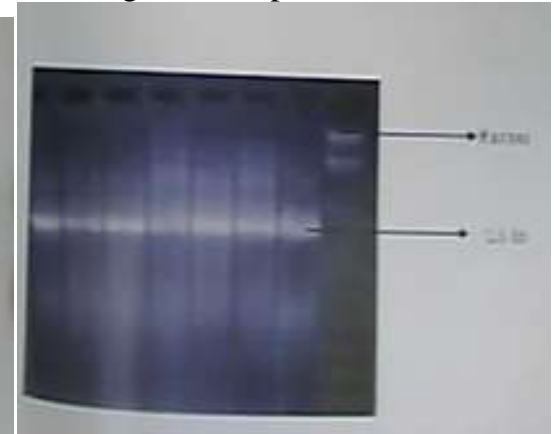

